\title{
EphB Regulates L1 Phosphorylation during Retinocollicular Mapping
}

\author{
Jinxia Daia, ${ }^{\mathrm{a}}$, Jasbir S. Dalal ${ }^{\mathrm{a}, \S, 1}$, Sonal Thakar ${ }^{\mathrm{b}, 2}$, Mark Henkemeyer $^{\mathrm{b}}$, Vance P. Lemmon ${ }^{\mathrm{c}}$, \\ Jill S. Harunaga ${ }^{a, 3}$, Monika C. Schlatter ${ }^{a, 4}$, Mona Buhusi ${ }^{a, 5}$, and Patricia F. Maness ${ }^{a,{ }^{*}}$ \\ aDepartment of Biochemistry and Biophysics, University of North Carolina, Chapel Hill, NC \\ 27599, USA \\ bDepartment of Developmental Biology, Kent Waldrep Center for Basic Research on Nerve \\ Growth and Regeneration, University of Texas Southwestern Medical Center, Dallas, Texas \\ 75390-9133, USA \\ 'The Miami Project to Cure Paralysis, Department of Neurological Surgery, University of Miami \\ Miller School of Medicine, Miami, FL 33136, USA
}

\begin{abstract}
Interaction of the cell adhesion molecule L1 with the cytoskeletal adaptor ankyrin is essential for topographic mapping of retinal ganglion cell (RGC) axons to synaptic targets in the superior colliculus (SC). Mice mutated in the L1 ankyrin-binding motif $\left(\right.$ FIGQY $\left.{ }^{1229} \mathrm{H}\right)$ display abnormal mapping of RGC axons along the mediolateral axis of the SC, resembling mouse mutant phenotypes in EphB receptor tyrosine kinases. To investigate whether L1 functionally interacts with EphBs, we investigated the role of EphB kinases in phosphorylating L1 using a phosphospecific antibody to the tyrosine phosphorylated FIGQY ${ }^{1229}$ motif. EphB2, but not an EphB2 kinase dead mutant, induced tyrosine phosphorylation of L1 at FIGQY ${ }^{1229}$ and perturbed ankyrin recruitment to the membrane in L1-transfected HEK293 cells. Src family kinases mediated L1 phosphorylation at FIGQY ${ }^{1229}$ by EphB2. Other EphB receptors that regulate medial-lateral retinocollicular mapping, EphB1 and EphB3, also mediated phosphorylation of L1 at FIGQY ${ }^{1229}$. Tyrosine $^{1176}$ in the cytoplasmic domain of L1, which regulates AP2/clathrin-mediated endocytosis and axonal trafficking, was not phosphorylated by EphB2. Accordingly mutation of $\mathrm{Tyr}^{1176}$ to Ala in $\mathrm{L} 1-\mathrm{Y}^{1176} \mathrm{~A}$ knock-in mice resulted in normal retinocollicular mapping of ventral RGC axons. Immunostaining of the mouse SC during retinotopic mapping showed that L1 colocalized with
\end{abstract}

\footnotetext{
(C) 2012 Elsevier Inc. All rights reserved.

*Corresponding author. phone: (919)966-3532; fax: (919)966-2852; srclab@ med.unc.edu.

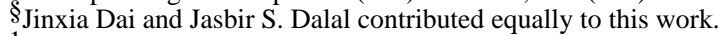

1Present address: Department of Genetics, Washington University, St. Louis, MO 63110, USA

2Present address: Neurobiology Section, Biological Sciences Division, University of California, San Diego, La Jolla, CA 92093, USA

${ }^{3}$ Present address: Laboratory of Cell and Developmental Biology, National Institute of Dental and Craniofacial Research, National Institutes of Health, Bethesda, MD 20892-4370, USA

${ }^{4}$ Present address: Institute of Pharmacology and Toxicology, University of Zurich, CH-8057 Zurich, Switzerland

5 Present address: Department of Neurosciences, Medical University of South Carolina, Charleston, SC 29425, USA

Publisher's Disclaimer: This is a PDF file of an unedited manuscript that has been accepted for publication. As a service to our customers we are providing this early version of the manuscript. The manuscript will undergo copyediting, typesetting, and review of the resulting proof before it is published in its final citable form. Please note that during the production process errors may be discovered which could affect the content, and all legal disclaimers that apply to the journal pertain.
} 
phospho-FIGQY in RGC axons in retinorecipient layers. Immunoblotting of SC lysates confirmed that $\mathrm{L} 1$ was phosphorylated at FIGQY ${ }^{1229}$ in wild type but not L1-FIGQY ${ }^{1229} \mathrm{H}\left(\mathrm{L} 1 \mathrm{Y}^{1229} \mathrm{H}\right)$ mutant SC, and that L1 phosphorylation was decreased in the EphB2/B3 mutant SC. Inhibition of ankyrin binding in $\mathrm{L} 1 \mathrm{Y}^{1229} \mathrm{H}$ mutant RGCs resulted in increased neurite outgrowth compared to WT RGCs in retinal explant cultures, suggesting that L1-ankyrin binding serves to constrain RGC axon growth. These findings are consistent with a model in which EphB kinases phosphorylate L1 at FIGQY ${ }^{1229}$ in retinal axons to modulate L1-ankyrin binding important for mediolateral retinocollicular topography.

\section{Keywords}

EphB receptor; L1; tyrosine phosphorylation; FIGQY domain; ankyrin; retinocollicular mapping

\section{Introduction}

The projection of retinal ganglion cell (RGC) axons to the superior colliculus (SC) is a wellestablished system for studying highly ordered topographic mapping in the central nervous system. In this projection, axons from the temporal-nasal axis of the retina project to the SC along its anterior-posterior axis mediated by interaction of complementary gradients of repellent ephrinA ligands in the SC and EphA receptor tyrosine kinases in the retina (Feldheim et al., 2000; Frisen et al., 1998; Hansen et al., 2004; Lemke and Reber, 2005; Yates et al., 2001). Conversely, RGC axons from the dorsal-ventral axis of the retina project to the lateral-medial axis in SC mediated by counter gradients of ephrinB1 in the SC and EphB receptors (B1, B2, B3) in the retina (Hindges et al., 2002; Lemke and Reber, 2005; McLaughlin et al., 2003; Thakar et al., 2011).

The L1 neural cell adhesion molecule contributes to mediolateral retinocollicular topography through its ability to engage the actin cytoskeletal adaptor ankyrin (Buhusi et al., 2008; Demyanenko and Maness, 2003). L1 is an immunoglobulin (Ig)-class transmembrane glycoprotein that consists of an extracellular region of 6 Ig-like and 5 fibronectin type III repeats, a single-pass transmembrane region, and a short cytoplasmic domain (Moos et al., 1988). L1 is expressed on developing axons and growth cones in discrete regions of the nervous system, where it regulates axon fasciculation and guidance (Maness and Schachner, 2007). A motif in the cytoplasmic domain of L1 FIGQY ${ }^{1229}$ binds ankyrin reversibly (Fig. 1A), thus regulating L1 linkage to the actin cytoskeleton through ankyrin-spectrin bindings (Davis and Bennett, 1994; Yap et al., 2008). L1-ankyrin binding is associated with stable adhesive contacts and inhibition of retrograde actin flow (Gil et al., 2003; Nishimura et al., 2003; Whittard et al., 2006), whereas tyrosine phosphorylation of FIGQY abolishes ankyrin binding and decreases adhesion (Garver et al., 1997; Jenkins et al., 2001). The serine/ threonine kinase ERK/MAP kinase has been shown to lie upstream of FIGQY phosphorylation (Whittard et al., 2006). Another key tyrosine-containing motif $\mathrm{Y}^{1176} \mathrm{RSL}$ that can be phosphorylated in the L1 cytoplasmic domain binds the AP2 clathrin adaptor and ezrin-radixin-moesin (ERM) proteins, which engage the actin cytoskeleton (Fig. 1A). This motif regulates endocytosis and trafficking of L1 during neurite outgrowth (Cheng et al., 
2005; Kamiguchi and Lemmon, 1998; Kamiguchi et al., 1998; Wisco et al., 2003), however, a role in retinocollicular mapping has not been addressed.

Mutation of tyrosine ${ }^{1229}$ in the FIGQY motif of $\mathrm{L} 1$ to histidine $\left(\mathrm{L} 1 \mathrm{Y}^{1229} \mathrm{H}\right)$ in mice blocks ankyrin binding and disrupts retinocollicular mapping specifically along the mediolateral axis of the SC (Buhusi et al., 2008). In $\mathrm{L} 1 \mathrm{Y}^{1229} \mathrm{H}$ mutant mice, axons from the ventral retina, which express higher levels of EphB receptors than those from dorsal retina, mistarget to inappropriately lateral sites in the SC, where they form multiple ectopic arborizations (Buhusi et al., 2008). Mediolateral mistargeting in $\mathrm{L} 1 \mathrm{Y}^{1229} \mathrm{H}$ mutants is phenocopied in EphB1, EphB2, EphB3 single and variant double knockout mice, as well as in EphB1- or EphB2 kinase-inactive mutant mice (Hindges et al., 2002; Thakar et al., 2011). This evidence raised the possibility that ephrinB/EphB signaling might regulate L1 phosphorylation and ankyrin binding important for mediolateral retinocollicular axon mapping in the SC.

Here we show that EphB receptors induce tyrosine phosphorylation of L1 at FIGQY ${ }^{122}$ to modulate ankyrin binding. Inhibition of ankyrin binding in $\mathrm{L}^{1} \mathrm{Y}^{1229} \mathrm{H}$ mutant RGCs increased RGC neurite outgrowth in ventral retina explants, suggesting that L1-ankyrin binding serves to constrain RGC axon growth. In contrast, mutation of tyrosine in the L1$\mathrm{Y}^{1176} \mathrm{RSL}$ motif to alanine did not alter retinocollicular mapping, and EphB did not phosphorylate the $\mathrm{Y}^{1176} \mathrm{RSL}$. These findings are consistent with a model in which EphB kinases regulate ankyrin binding to L1 through tyrosine phosphorylation at the L1 FIGQY motif, in this way modulating RGC axon growth for appropriate targeting of retinal axons along the mediolateral axis of the SC.

\section{Results}

\section{EphB receptor mediates tyrosine phosphorylation of L1 in the ankyrin binding motif FIGQY}

EphB2 is the most prominent EphB receptor exhibiting graded expression in the mouse retina along the dorsal-ventral axis during retinocollicular mapping from postnatal day 0 to10 (P0-P10), where it cooperates with EphB1 and EphB3 to regulate responses of RGC axons to the mediolateral SC gradient of ephrinB1 (Hindges et al., 2002; Thakar et al., 2011). To investigate whether EphB2 kinase was capable of phosphorylating L1 on $\mathrm{Y}^{1229}$ in the FIGQY ankyrin binding motif, L1 and EphB2 were co-expressed in HEK293 cells, and phosphorylation of $\mathrm{L} 1$ at $\mathrm{Y}^{1229}$ was analyzed by immunoblotting with a phospho-specific antibody recognizing the tyrosine phosphorylated FIGQY sequence (p-FIGQY). This antibody was raised against a peptide encompassing the FIGQY sequence of L1, similar to a previously described phospho-FIGQY antibody raised against the homologous sequence in Neurofascin (Jenkins et al., 2001; Kizhatil et al., 2002). In cells expressing L1 and EphB2, phosphorylation of L1 at FIGQY was strongly increased compared to L1 in cells not expressing EphB2 (Fig. 1B). Both differentially glycosylated forms of mature L1 protein (200, 220kDa) (He et al., 2009) were recognized by p-FIGQY antibody and showed increased phosphorylation by EphB2. A low level of p-FIGQY was seen in cells transfected with L1 alone, which was likely due to endogenous tyrosine kinases. Treatment of cells with the EphB ligand ephrinB1 did not increase p-FIGQY levels in cells expressing L1 with or 
without EphB2 (Fig. 1B), probably due to autoactivation typically resulting from overexpressed receptor kinases. The specificity of the p-FIGQY antibody for L1 phosphorylated on $\mathrm{Y}^{1229}$ was demonstrated by immunoblotting of L1 immunoprecipitated from HEK293 cells expressing the L1 $\mathrm{Y}^{1229} \mathrm{H}$ mutant (L1YH). No p-FIGQY signal was evident in $\mathrm{L}_{1} \mathrm{Y}^{1229} \mathrm{H}$ from cells with or without EphB2 co-expression (Fig. 1C).

To investigate the specificity of EphB receptors in phosphorylating L1, EphB1and EphB3 were similarly evaluated, as they are also involved in mediolateral retinocollicular targeting (Hindges et al., 2002; Thakar et al., 2011). EphB2, EphB1 and EphB3 of mouse origin were all capable of phosphorylating L1 at FIGQY, however EphB2 of chick origin (cEphB2) always elicited higher phosphorylation of L1 (Fig. 1D). To evaluate the ability of EphBs to co-immunoprecipitate with L1, blots were reprobed with antibodies recognizing cEphB2 and $\mathrm{mEphB} 2$ or anti-HA antibody recognizing HA-tagged mEphB1 and mEphB3. Results showed that each of the EphBs coimmunoprecipitated with L1, thus indicating a direct or indirect molecular association (Fig. 1D). To determine if the kinase activity of EphB2 was essential for the phosphorylation of FIGQY, a chicken kinase-dead EphB2 mutant (EphB2K662R; EphB2 KD) (Zisch et al., 1998) was cotransfected with L1 into HEK293 cells, then L1 was analyzed in immunoprecipitates by immunoblotting with p-FIGQY antibody. Unlike WT EphB2, EphB2 KD did not support L1 phosphorylation at the FIGQY motif (Fig. 1E).

The non-receptor tyrosine kinase, $\mathrm{pp} 60^{\mathrm{c}-\mathrm{src}}$, is recruited to activated EphB receptors including EphB2 by binding with two conserved phosphorylated tyrosine in the juxtamembrane of EphB2 (Vindis et al., 2003; Zisch et al., 1998; Zisch et al., 2000). To assess whether Src family members might be involved in tyrosine phosphorylation of L1 at FIGQY by EphBs, the Src family kinase inhibitor PP2 was added to HEK293 cells expressing L1 and EphB2. Phosphorylation of L1 at FIGQY by EphB2 was completely inhibited by PP2 (Fig. 1E). In contrast, the nonfunctional analog PP3 did not decrease the pFIGQY level on L1 (Fig. 1E). Therefore, pp60 ${ }^{\mathrm{c}-s r c}$ or another Src-related family kinase, such as pp59 $9^{\mathrm{c}-\mathrm{fyn}}$ or pp62 $2^{\mathrm{c}-\mathrm{yes}}$, may function as a downstream effector of EphB2 kinase in phosphorylating L1 at FIGQY.

\section{Tyrosine ${ }^{1176}$ in the YRSL motif of L1 is neither phosphorylated by EphB nor involved in retinocollicular mapping}

L1 engages the clathrin adapter AP2 and ERM proteins at Tyr ${ }^{1176}$ located within the YRSL motif of the L1 cytoplasmic domain. This sequence can be phosphorylated by pp60 ${ }^{\mathrm{c}-\mathrm{src}}$ on $\mathrm{Tyr}^{1176}$ (Schaefer et al., 2002), and is important for AP2/clathrin-mediated endocytosis and axonal trafficking (Kamiguchi and Lemmon, 1998; Kamiguchi et al., 1998; Wisco et al., 2003) during growth cone navigation (Itofusa and Kamiguchi, 2011). ERMs mediate L1induced axon branching (Cheng et al., 2005) and guidance (Mintz et al., 2008), as well as Semaphorin3A-induced growth cone collapse (Mintz et al., 2008; Schlatter et al., 2008). To examine whether EphB2 was able to phosphorylate L1 on tyrosine in the $\mathrm{Y}^{1176} \mathrm{RSL}$ motif, we took advantage of a phosphorylation-state specific antibody (74-5H7) that recognizes only the non-phosphorylated $\mathrm{Y}^{1176} \mathrm{RSL}$ sequence (Schaefer et al., 2002). L1 was immunoprecipitated from lysates of HEK293 cells expressing L1 alone or L1 and EphB2, 
and the levels of non-phosphorylated L1- $\mathrm{Y}^{1176} \mathrm{RSL}$ were compared by immunoblotting with 74-5H7 antibody. No differences were observed in the relative levels of non-phosphorylated L1 at $\mathrm{Y}^{1176} \mathrm{RSL}$ detected by this antibody in L1-expressing HEK293 cells with or without EphB2 (Fig. 1F). These results indicated that overexpressed EphB2 was unable to induce tyrosine phosphorylation of $\mathrm{L} 1$ at $\mathrm{Y}^{1176} \mathrm{RSL}$ in HEK293 cells.

Mutation of L1 Tyr ${ }^{1176}$ to alanine inhibits AP2 and ERM binding (Cheng et al., 2005; Dickson et al., 2002). Knock-in mice with this point mutation (L1 $\left.\mathrm{Y}^{1176} \mathrm{~A}\right)$ display normal brain morphology (Nakamura et al., 2010) but they have not been examined for consequences on retinocollicular mapping. To investigate whether mediolateral mapping of RGC axons from the ventral retina to the SC was perturbed by mutation of $\mathrm{L} 1 \mathrm{Tyr}^{1176}$ to alanine, we performed axon tracing in homozygous $\mathrm{L} 1 \mathrm{Y}^{1176} \mathrm{~A}$ and $\mathrm{L} 1 \mathrm{Y}^{1229} \mathrm{H}$ mutant mice, as well as WT controls by injecting DiI into the ventro-temporal retina at P10-12, and comparing the location of termination zones (TZs) in the SC after 48 hour. Ventro-temporal axons express high levels of EphB receptors and normally project to the anteromedial SC, thus their attraction to the medial-high ephrinB1 gradient in the SC makes them very sensitive to alterations in mediolateral targeting controlled by ephrinB1/EphB signaling (Hindges et al., 2002; Thakar et al., 2011). DiI injection into the ventro-temporal retina labeled a single TZ in the anteromedial SC of WT mice and multiple, laterally-displaced ectopic TZs in the SC of $\mathrm{L} 1 \mathrm{Y}^{1229} \mathrm{H}$ mice (Fig. 2), as shown previously (Buhusi et al., 2008). DiI injections into the ventro-temporal retina of $\mathrm{L} 1 \mathrm{Y}^{1176} \mathrm{~A}$ mutant mice resulted in normally positioned TZs in the anteromedial SC in all cases (7/7 mice) (Fig. 2). In all L1 $\mathrm{Y}^{1176} \mathrm{~A}$ null mutants, a single, dense TZ was located in an appropriate location along both the mediolateral and anteroposterior axes of the SC. Thus, interactions mediated by the YRSL motif in the L1 cytoplasmic domain did not appear to be critical determinants of retinocollicular mapping in the mediolateral axis, underscoring the importance of the ankyrin binding domain of L1 in EphB-mediated retinal axon guidance.

\section{EphB2 inhibits recruitment of ankyrin to the membrane of L1-expressing cells by phosphorylation of the ankyrin binding motif FIGQY}

Tyrosine phosphorylation of the highly conserved FIGQY domain of L1 family members abolishes ankyrin binding (Garver et al., 1997). The missense mutation $\mathrm{Y}^{1229} \mathrm{H}$ of $\mathrm{L} 1$ FIGQY domain abolishes ankyrin recruitment to L1 in vivo and in a cellular recruitment assay to the membrane in L1-expressing HEK293 cells (Buhusi et al., 2008; Needham et al., 2001). To evaluate the ability of EphB2 to modulate L1-ankyrin binding, we used the cytofluorescence assay as described by Needham et al (2001) which measures L1-dependent recruitment of EGFP-labeled ankyrinG from the cytoplasm to the plasma membrane in transfected HEK293 cells (Needham et al., 2001). Expression of EGFP-ankyrinG alone resulted in diffuse EGFP fluorescence in the cytoplasm, whereas co-expression of L1 and EGFP-ankyrinG resulted in recruitment of fluorescence to the plasma membrane where L1 was localized (Fig. 3A), in accord with previous results (Needham et al., 2001). When EphB2 was co-expressed with L1 under conditions shown to result in tyrosine phosphorylation at FIGQY, EGFP-ankyrinG remained distributed throughout the cytoplasm (Fig. 3A). The observation that a percentage of cells expressing L1 and EphB2 displayed residual ankyrinG recruitment to the membrane suggested that L1 may be incompletely 
phosphorylated. In contrast, co-expression of the EphB2 KD mutant with L1 led to the recruitment of ankyrinG to the membrane (Fig. 3A).

Quantification of these results showed that greater than $70 \%$ of cells co-expressing L1 and EGFP-ankyrinG displayed recruitment of ankyrinG to the membrane, which was significantly greater than the percent of cells expressing EGFP-ankyrinG alone (18\%) (Fig. 3B). In cells co-expressing L1 and EphB2 the percent of cells exhibiting ankyrinG recruitment to the membrane significantly decreased, and further decreased with ephrinB1Fc treatment (Fig. 3B). In cells co-expressing L1 and EphB2 KD the percent of cells exhibiting ankyrinG recruitment was equal to that of L1 alone (Fig. 3B). Co-expression of $\mathrm{L} 1 \mathrm{Y}^{1229} \mathrm{H}$ and EGFP-ankyrinG with or without EphB2, or with EphB2 under ephrinB1 treatment did not induce recruitment of ankyrin to the plasma membrane at a level similar to that of cells expressing EGFP-ankyrinG alone (Fig. 3B). The phosphorylation of L1 by EphB2 was confirmed by positive p-FIGQY immunoblotting of L1 immunoprecipitated from lysates of EGFP-ankyrinG-expressing HEK293 cells transfected with L1/EphB2 but not with L1/EphB2 KD or L1 $\mathrm{Y}^{1229} \mathrm{H}$ (with or without EphB2) (Fig. 3C). These results were consistent with the interpretation that phosphorylation of L1 at the FIGQY motif by EphB2 kinase reduces L1-ankyrin interaction in a cellular context.

\section{The FIGQY domain of L1 is phosphorylated in retinal ganglion cell axons in the superior colliculus}

Retinocollicular targeting in mouse begins from embryonic day 14 (E14), when RGC axons first reach the SC, to postnatal day 10 (P10), when topographic mapping is largely completed (Simon and O'Leary, 1992). The map is further refined in an activity-dependent manner after eye opening around P12 (Schmidt, 2004). Studies in vitro and in vivo have demonstrated a pivotal role for the ankyrin binding motif of L1 (FIGQY) in retinocollicular mapping (Buhusi et al., 2008; Hortsch et al., 2009). To determine whether L1 was phosphorylated at FIGQY on retinal axons during retinocollicular mapping in vivo, we evaluated the co-localization of L1 and p-FIGQY immunoreactivity within the early postnatal SC of the mouse during retinal axon navigation (P7) by double immunofluorescence staining. L1 and p-FIGQY immunoreactivity were observed in fibers within the superficial layers of the SC (stratum griseum superficiale (SGS) and stratum opticum (SO)), where incoming RGC axons are localized at this stage (Fig. 4A). A portion of the p-FIGQY immunofluorescence was punctate and co-localized with L1 in fibers within the superficial layers, as indicated in merged images (Fig. 4A). Additional p-FIGQY immunofluorescence did not co-localize with L1 but was evident in some fibers within the retinorecipient layers, as well as in a non-fibrous pattern in other laminae of the SC. Control staining with nonimmune IgG was minimal.

When L1 was immunoprecipitated from WT SC lysates at P3 and immunoblotted with pFIGQY antibody, labeled proteins corresponded to intact L1 (220 kDa) and its most abundant carboxyl terminal cleavage fragment $(80 \mathrm{kDa})$, which is generated in mouse brain by a proprotein convertase (Kalus et al., 2003) (Fig. 4B, upper panel). Reprobing with a monoclonal antibody against the L1 carboxyl terminus confirmed the identity of these protein bands as L1 (Fig. 4B, upper panel). L1 phosphorylated at FIGQY in SC lysates was 
also recognized by a general phosphotyrosine-specific antibody (Fig. 4B, lower panel).

Other L1 family members CHL1, Neurofascin (NF), and NrCAM were also expressed in the P3 SC as shown by immunoprecipitation and immunoblotting with respective antibodies from SC lysates (Fig. 4B, lower panel). Due to the close homology between L1 and NrCAM within the FIGQY-containing sequence, the p-FIGQY antibody recognized a very small amount of NrCAM immunoprecipitated from the SC lysates, but no p-FIGQY signal was detected in CHL1 or Neurofascin at equivalent exposures to that used for L1 (Fig. 4B, lower panel). Thus, p-FIGQY staining in fibers not co-localizing with L1, might represent low levels of NrCAM expressed on RGC axons. As a further negative control, the p-FIGQY antibody clearly did not recognize L1 lacking Tyr ${ }^{1229}$ immunoprecipitated from $\mathrm{L} 1 \mathrm{Y}^{122}{ }^{12} \mathrm{H}$ mutant SC at P3 (Fig. 4C). These results were consistent with tyrosine phosphorylation of L1 at FIGQY ${ }^{1229}$ in RGC axons within the SC during early stages of postnatal targeting.

To investigate whether the expression of EphB receptors is correlated with phosphorylation of L1 at FIGQY in the SC, L1 was immunoprecipitated from SC lysates of WT and EphB2/B3 double knockout (DKO) mice at P5, and immunoblotted with p-FIGQY antibody. The $220 \mathrm{kDa}$ L1 band recognized by p-FIGQY antibody in WT SC was decreased in the EphB2/B3 DKO SC, despite equivalent amounts of L1 in immunoprecipitates (Fig. 4D). Quantification of results from multiple mice showed that the ratio of p-FIGQY to L1 in the $220 \mathrm{kDa}$ band of EphB2/B3 DKO SC (40 $\pm 2 \%$, Means \pm S.E.M., $\mathrm{n}=6)$ was significantly lower $(\sim 30 \%)$ than that in WT SC $(58 \pm 1 \%$, Means \pm S.E.M., $n=3)$ (t-test, $\mathrm{p}<0.001)$. The residual p-FIGQY present in L1 may be due to phosphorylation by EphB1 or another tyrosine kinase, or may derive from p-FIGQY positive cells that were not located in the superficial retinorecipient layers of the SC.

\section{Effect of FIGQY mutation on regulation of retinal axon outgrowth in explant cultures}

Dorsal-ventral differences in RGC axon responses to ephrinB gradients are difficult to observe in culture as previously discussed (Hindges et al., 2002). Therefore, the consequences of FIGQY mutation on RGC neurite outgrowth were analyzed in a model system in which retinal explants from WT and $\mathrm{L} 1 \mathrm{Y}^{1229} \mathrm{H}$ mutant mice (P3) were cultured on fibronectin/poly-lysine. It was previously shown that L1-ankyrin binding enhances integrindependent adhesion of retinal cells to fibronectin (Buhusi et al., 2008), a substrate present on radial glia in the SC/optic tectum (Stettler and Galileo, 2004). Neurite growth in this assay is also promoted by shed L1 extracellular fragments adhering to the substrate (Mechtersheimer et al., 2001). After 3 days in vitro, WT retinal explants displayed evident outgrowth of RGC neurites, as visualized by immunofluorescence staining with TuJ1 antibody to $\beta$ III tubulin (Fig. 5B). There was no difference in neurite growth from retinal explants isolated from the dorsal or ventral quarters of the WT retina (Fig. 5A), in accord with results from Hansen et al., (Hansen et al., 2004) who showed no differences in neurite growth of explants derived from different axial positions in the mouse retina. Neurite outgrowth of RGCs from $\mathrm{L} 1 \mathrm{Y}^{1229} \mathrm{H}$ ventral explants was substantially greater than that of WT (Fig. 5A,B). Some neurites from $\mathrm{L} 1 \mathrm{Y}^{1229} \mathrm{H}$ mutants extended far from the explants, in addition to some with comparable length to WT (Fig. 5B). Axon outgrowth was quantified in multiple explant cultures by measuring length of TuJ1-positive neurites extending from the edge of the explant to the periphery. Outgrowth of RGC axons from retinal explants of $\mathrm{L}_{1} \mathrm{Y}^{1229} \mathrm{H}$ 
mutant mice was significantly greater than that of WT (Fig. 5A; t-test, $\mathrm{p}<0.05$ ).

Immunofluorescence staining of the explant cultures with p-FIGQY antibody showed that WT retinal neurites displayed L1 phosphorylation, not observed in L1 $\mathrm{Y}^{1229} \mathrm{H}$ neurites (Fig. 5C). WT L1 phosphorylation was likely due to endogenous receptor tyrosine kinases activated by growth factors in the medium. Increased neurite growth of $\mathrm{L}^{1} \mathrm{Y}^{1229} \mathrm{H}$ RGCs may be due to decreased adhesion, as integrin-dependent adhesion to fibronectin was decreased in $\mathrm{L}_{1} \mathrm{Y}^{1229} \mathrm{H}$ mutant RGCs (Buhusi et al., 2008).

Furthermore, studies of sensory and cerebellar neurons treated with peptide inhibitors of L1ankyrin binding, or ankyrinB null mice suggest that L1-ankyrin binding fosters stationary behavior by inhibiting retrograde actin flow (Gil et al., 2003; Nishimura et al., 2003). Whether such a mechanism extends to axon branch attraction in the SC induced by ephrinB/ EphB is not clear. Our results with RGCs from $\mathrm{L}_{1} \mathrm{Y}^{1229} \mathrm{H}$ mutant mice support an interpretation that phosphorylation of L1 at the FIGQY motif promotes neurite outgrowth of RGCs, potentially by reducing stationary behavior and adhesion.

\section{Discussion}

Here we show that EphB receptor tyrosine kinases interact with L1 by regulating tyrosine phosphorylation at the ankyrin binding motif FIGQY in the L1 cytoplasmic domain and that this modification modulates ankyrin binding, a key molecular interaction important for mediolateral retinocollicular axon targeting. EphB2 kinase induced phosphorylation of L1 at the FIGQY motif and inhibited ankyrin recruitment to cell membrane expressing L1 in HEK293 cells in vitro. EphB1 and EphB3, in addition to EphB2 were capable of associating with L1 and phosphorylating L1 at the FIGQY motif. Moreover, $\mathrm{Tyr}^{1229}$ within the FIGQY motif of L1 was phosphorylated in retinal axons in the SC of early postnatal WT mice during retinocollicular axon mapping, and this phosphorylation decreased in the SC of mice deficient in EphB2 and EphB3, and was completely lost in $\mathrm{L} \mathrm{Y}^{1229} \mathrm{H}$ mutant SC. In contrast $\mathrm{Tyr}^{1176}$ in the L1 YRSL motif, which is a critical determinant of AP2/clathrin and ERM binding, was not phosphorylated by EphB2, and mutation of this motif in L1 $\mathrm{Y}^{1176} \mathrm{RSL}$ mutant mice did not impair retinocollicular mapping. These findings implicate EphB receptor signaling in regulating L1 phosphorylation at $\mathrm{Tyr}^{1229}$ as a critical modulator of ankyrin interactions occurring during retinocollicular axon targeting.

EphB1, EphB2, and EphB3 were able to phosphorylate L1 at FIGQY and to associate with L1 in vitro, thus each receptor has the potential to regulate L1-ankyrin interactions during retinocollicular axon targeting. EphB1, EphB2, and EphB3 null mutant mice, as well as EphB1- and EphB2 kinase-inactive mutants, exhibit mediolateral SC mistargeting of ventral retinal axons, similar to the phenotype of $\mathrm{L} 1 \mathrm{Y}^{1229} \mathrm{H}$ mutant mice (Buhusi et al., 2008; Hindges et al., 2002; Thakar et al., 2011). Enhancement of the mistargeting phenotype by double deletion of EphB2 and EphB3, and other specific EphB combinations, implicates multiple EphBs in mediolateral mapping (Thakar et al., 2011). Based on inhibition of EphB2-induced phosphorylation of L1 in the presence of a selective Src inhibitor PP2, Src family kinases downstream of EphBs may mediate phosphorylation of L1 at the FIGQY motif. Among the Src family kinases expressed in neurons (pp60 $0^{\mathrm{c}-\mathrm{src}}, \mathrm{p} 59^{\mathrm{fyn}}, \mathrm{p} 62^{\mathrm{c}-\mathrm{yes}}$ ), pp60 $60^{c-s r c}$ is a good candidate as it is known to be recruited to activated EphB receptors 
(Vindis et al., 2003; Zisch et al., 1998) and it regulates neurite outgrowth of cerebellar neurons on L1 (Ignelzi et al., 1994). However, pp60 ${ }^{\mathrm{c}-\mathrm{src}}$ does not promote phosphorylation of L1 at FIGQY in all cells and pathways (Schaefer et al., 2002; Whittard et al., 2006). Our findings are in agreement with an earlier report showing that co-transfection of L1 and the chicken EphB2 homologue Cek5 into a glioblastoma cell line induces L1 tyrosine phosphorylation, although the tyrosine residue was not identified (Zisch et al., 1997).

Overall, the results are consistent with the interaction between L1 and EphB receptors that activates forward EphB2 signaling through pp60 $0^{\mathrm{c}-\mathrm{src}}$ to induce FIGQY phosphorylation. It is not excluded that EphB and L1 also function in the SC to modulate RGC axon navigation through reverse signaling, as shown in retinal cell cultures (Suh et al., 2004). Regulation of ankyrin binding by EphB-mediated tyrosine phosphorylation of L1 at FIGQY may promote axon growth and branch orientation of ventral RGCs toward the medial-high ephrinB1 in the SC. In support of this, outgrowth of ventral RGC axons from $\mathrm{L}_{1} \mathrm{Y}^{1229} \mathrm{H}$ mutant mice was greater than that of WT in explant cultures. An analogous role for L1-ankyrin binding in constraining neurite outgrowth has been described for cerebellar and hippocampal neurons (Boiko et al., 2007; Gil et al., 2003; Whittard et al., 2006).

In contrast to the FIGQY ankyrin binding motif, the YRSL sequence in the L1 cytoplasmic domain did not play a significant role in retinocollicular mapping. Mutation of $\mathrm{Tyr}^{1176}$ to Ala in the YRSL motif did not alter mediolateral or anteroposterior mapping of retinal axons in the mouse SC. Although L1 $\mathrm{Tyr}^{1176}$ can be phosphorylated by pp60 ${ }^{\mathrm{c}-\mathrm{src}}$ in vitro and in vivo (Schaefer et al., 2002), it did not induce L1 phosphorylation at this site in EphB2expressing HEK293 cells. Because this sequence is involved in regulating AP2/clathrinmediated endocytosis, ERM interactions, and axon trafficking (Cheng et al., 2005;

Kamiguchi and Lemmon, 1998; Kamiguchi et al., 1998; Wisco et al., 2003), these functions may not play a major role in topographic targeting of ventro-temporal axons.

Our findings suggest a model in which ephrinB1/EphB induces tyrosine phosphorylation of L1 at FIGQY ${ }^{1229}$ through EphB and Src kinase activity, decreasing ankyrin binding and promoting RGC axon growth and/or branch attraction to terminations zones along the mediolateral gradient of ephrinB1 (Fig. 6).

Dephosphorylation of L1-FIGQY through tyrosine phosphatases would conversely increase ankyrin binding and spectrin-mediated linkage to the actin cytoskeleton, potentially stabilizing synaptic terminals. In an analogous manner, ankyrin binding to nonphosphorylated FIGQY in L1 family proteins is associated with cessation of axon growth and formation of synapses (Ango et al., 2004; Boiko et al., 2007; Gil et al., 2003; Godenschwege et al., 2006; Hortsch et al., 2009; Nishimura et al., 2003; Tuvia et al., 1997). The mutation $\mathrm{L} 1 \mathrm{Y}^{1229} \mathrm{H}$ inhibits ankyrin binding and thus could decrease adhesion/ stabilization of RGC axons at termination zones in retinocollicular axon targeting. The residual p-FIGQY of L1 in EphB2/B3 double null mutant mice suggests that other signaling pathways participate in phosphorylation of the FIGQY ankyrin binding motif. For example, nerve growth factor (NGF), fibroblast growth factor (FGF), and epidermal growth factor (EGF) promote phosphorylation of L1 proteins at highly conserved FIGQY domains (Garver et al., 1997; Gil et al., 2003; Tuvia et al., 1997; Whittard et al., 2006). Among these, FGF 
signaling has a demonstrated role in retinotectal mapping in Xenopus (McFarlane et al., 1996) and influences EphB2 phosphorylation (Poliakov et al., 2008). In addition brainderived neurotrophic factor (BDNF) signaling through TrkB serves as a branch promoting factor for retinal axons (Feldheim and O'Leary, 2010; Poopalasundaram et al., 2011). Thus, growth factor and ephrinB/EphB signaling pathways might converge at the level of cell adhesion molecule phosphorylation to coordinately regulate ankyrin binding and modulate retinal axon growth and branch migration within the SC.

In summary, our findings demonstrate that $\mathrm{EphB}$ receptors function in regulating phosphorylation of the L1 ankyrin binding motif, and thus provide insight into the functional mechanism of cross-talk between ephrin/Eph signaling and cell adhesion molecules necessary for accurate retinocollicular topography.

\section{Experimental Methods}

Mice

L1 ${ }^{1229} \mathrm{H}$ (Buhusi et al., 2008) and L1 $\mathrm{Y}^{1176} \mathrm{~A}$ mutant mice (Nakamura et al., 2010) were previously characterized. Because the L1 gene is on the X chromosome, heterozygous females were crossed with C57BL6 WT males to obtain WT and hemizygous male mutants for analyses. Homozygous EphB2/EphB3 double null mutants (Hindges et al., 2002) were generated using protein null mouse mutants in EphB2 (Henkemeyer et al., 1996) and EphB3 (Orioli et al., 1996). Mice were used according to the Institutional Animal Care and Use Committee policies of the University of North Carolina at Chapel Hill and the University of Texas Southwestern Medical Center in accordance with National Institutes of Health guidelines.

\section{Production of p-FIGQY antibody}

The generation and characterization of p-FIGQY antibody was similar to those raised to the homologous phosphorylated peptide in rat Neurofascin (Jenkins et al., 2001). Affinity purified p-FIGQY antibody were raised in rabbits against a tyrosine phosphorylated peptide surrounding the FIGQY ${ }^{1229}$ ankyrin binding sequence (NEDGSFIGQ(pY)SGKKE) in mouse L1 and purified by Bethyl Laboratories, Inc. (Montgomery, TX) as described briefly below. The immunogen peptide CNEDGSFIGQ(pY)SGKKE was synthesized with an added cysteine residue at the $\mathrm{N}$-terminus and coupled to the immunogenic carrier protein keyhole limpet hemocyanin. Rabbits were immunized with the phospho-peptide and antibody was affinity-purified by processing over the non-phosphorylated FIGQY peptide immobilized to an immunosorbent column. The flow through was then purified on another immunosorbent column to which was coupled the phosphorylated FIGQY peptide. The antibody was eluted, stored in aliquots at $-70^{\circ} \mathrm{C}$, and characterized for recognition of $\mathrm{L} 1$ phosphorylated on $\mathrm{Tyr}^{1229}$ versus L1 $\mathrm{Y}^{1229} \mathrm{H}$ (negative control), and other L1 family members (CHL1, Neurofascin, NrCAM) by immunoblotting of transfected HEK293 cells and SC lysates (Fig. $1 \mathrm{C}$ and Fig. 4B,C). 


\section{Cell culture, brain lysates, immunoblotting, and immunoprecipitation}

HEK293T cells were cultured in DMEM with 10\% bovine fetal serum. Expression plasmids encoding human $\mathrm{L} 1$, human $\mathrm{L} 1 \mathrm{Y}^{1229} \mathrm{H}$, chicken EphB2 and EphB2 kinase dead mutant (EphB2K662R; EphB2 KD) (Zisch et al., 1998), mouse EphB1 containing a hemagglutinin epitope tag (HA), mouse EphB2 and mouse EphB3 containing HA-tag were transfected into HEK293T cells using Lipofectamine 2000 in Opti-MEM medium (Invitrogen) as described (Schlatter et al., 2008). After 48 hours, cells were washed with Hank's Balanced Salt Solution and lysates were prepared. In some experiments the Src family kinase inhibitor PP2 (4-amino-5-(4-chlorophenyl)-7-(t-butyl)pyrazolo[3,4-d]pyramidine) ( $2 \mu \mathrm{M}$; Calbiochem, Darmstadt, Germany) or its nonfunctional analogue PP3 (4-amino-7-phenylpyrazolo[3,4d]pyramidine) ( $2 \mu \mathrm{M}$; Calbiochem, Darmstadt, Germany) were added to cells for 20 minutes before lysis. For ephrinB1 treatment, $3 \mathrm{nM}$ mouse ephrinB1-Fc protein (R\&D Systems, Minneapolis, MN) preclustered with $0.3 \mathrm{nM}$ anti-human Fc (Jackson ImmunoResearch, West Grove, PA) for 30 minutes on ice were incubated with HEK293 cells in Opti-MEM for 15 minutes at $37{ }^{\circ} \mathrm{C}$ before lysis. Lysates of mouse superior colliculus (SC) were prepared as described (Buhusi et al., 2008). Transfected HEK293T cells or SC tissues were homogenized on ice in RIPA buffer containing protease inhibitors and phosphatase inhibitors (1\% NP-40, $1 \%$ sodium deoxcholate, $0.1 \%$ sodium dodecyl sulfate, $0.15 \mathrm{M} \mathrm{NaCl}$, $5 \mathrm{mM}$ Na-EDTA, $1 \mathrm{mM}$ Na-EGTA in $20 \mathrm{mM}$ Tris-HCl, pH 7.0, $10 \mu \mathrm{g} / \mathrm{mL}$ leupeptin, 0.11 $\mathrm{TIU} / \mathrm{mL}$ aprotinin, $0.2 \mathrm{mM}$ sodium orthovanadate, and $10 \mathrm{mM}$ sodium fluoride). Lysates were clarified by centrifugation at $14000 \mathrm{rpm}$. Protein concentration was measured by the BCA method (Pierce Biotechnology, Rockford, IL). Transfected cell lysates (500 $\mu \mathrm{g}$ ) were immunoprecipitated with mouse anti-L1 monoclonal (UJ127) antibody (1 $\mu \mathrm{g}$; Abcam, ab3200) or normal mouse IgG for $2 \mathrm{~h}$ at $4^{\circ} \mathrm{C}$, following incubation with protein A/GSepharose beads (Pierce Biotechnology, Rockford, IL) for 30 min at $4^{\circ} \mathrm{C}$. Beads were washed with RIPA buffer, and proteins were eluted by boiling in SDS-PAGE sample buffer. SC lysates $(1000 \mu \mathrm{g})$ were precleared with protein A/G-Sepharose beads for $30 \mathrm{~min}$ at $4^{\circ} \mathrm{C}$. For L1 immunoprecipitation, precleared lysates were incubated with mouse anti-L1

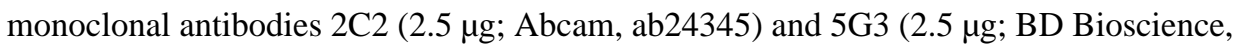
554273 ) for $2 \mathrm{~h}$ at $4^{\circ} \mathrm{C}$, then incubated with protein A/G-Sepharose beads for another $30 \mathrm{~min}$ at $4^{\circ} \mathrm{C}$. Beads were washed with RIPA and proteins were eluted by boiling in SDS-PAGE sample buffer. Similarly, immunoprecipitation of NrCAM, Neurofascin or CHL1 from P3 SC lysates were done by corresponding antibodies to $\mathrm{NrCAM}$ (Abcam, ab24344), Neurofascin (obtained from Dr. Peter Brophy) or CHL1 (R\&D systems, AF2147). The immunoprecipitates were resolved on 7.5\% SDS-PAGE gels and transferred to nitrocellulose membranes. After blocking in 5\% non-fat dry milk or 5\% BSA, the membranes were immunoblotted with antibodies to p-FIGQY (1:500), L1 (UJ127, 1:1000; Abcam, ab3200), L1 (2C2, 1:1000;; Abcam, ab24345), EphB2 (1:2000; Invitrogen, 36-6100), HA (1:1000; BaBco, HA-11), phosphotyrosine (1:1000; Cell Signaling Technology, 9411), NrCAM (0.4 ug/ml; Abcam, ab24344), CHL1 (1:1000; R\&D system, AF2147), Neurofascin (1:5000) or non-p-Y ${ }^{1176}$ RSL (74-5H7, 1:1000; provided by Dr. Vance Lemmon). Bands were developed on X-ray film by enhanced chemiluminescence (Perkin-Elmer, Waltham, MA), and quantified by densitometry. 


\section{Retinal explant cultures and neurite length measurements}

Retinal explants were prepared from the dorsal or ventral quarter of P3 WT and $\mathrm{L}^{1} \mathrm{Y}^{1229} \mathrm{H}$ mice as described previously (Wang et al., 2002). Mat-Tek plates were coated with $33 \mu \mathrm{g} / \mathrm{ml}$ poly-D lysine and followed by coating with $3 \mu \mathrm{g} / \mathrm{ml}$ fibronectin. Explants were cultured on the Mat-Tek plates in Neurobasal A medium containing $0.7 \%$ methyl cellulose, B27 supplement (Invitrogen) and $10 \mu \mathrm{g} / \mathrm{ml}$ gentimycin (Gibco BRL) for 3 days. Explants were fixed with $4 \%$ paraformaldehyde for 10 minutes and $0.2 \%$ Triton $\mathrm{x}-100$ in PBS for 2 minutes at room temperature for immunostaining of p-FIGQY (1:250), or the neuronal marker $\beta$ III tubulin using TuJ1 antibody (1:500; Covance). To quantify neurite outgrowth from retinal explants, the length $(\mu \mathrm{m})$ of 40 randomly selected neurites from each explant was measured and averaged using NIH Image J software. Mean neurite length of explant was calculated for multiple samples, and compared between genotypes by Student's t-test for significant differences $(\mathrm{P}<0.05)$.

\section{Immunofluorescence staining}

WT and $\mathrm{L} 1 \mathrm{Y}^{1229} \mathrm{H}$ mutant mice at postnatal day 7 (P7) were anesthetized with isoflurance and perfused transcardially with $4 \%$ paraformaldehyde (PFA) in $0.01 \mathrm{M}$ phosphate-buffered saline (PBS). The brains were post-fixed in $4 \%$ PFA overnight at $4{ }^{\circ} \mathrm{C}$ and sectioned in the sagittal plane $(16 \mu \mathrm{m})$ in a cryostat after cryoprotection with $30 \%$ sucrose in PBS. Sections were blocked in $2 \% \mathrm{BSA} / 10 \%$ normal donkey serum $/ 0.2 \%$ Triton $\mathrm{x}-100$ in PBS at $4{ }^{\circ} \mathrm{C}$ overnight. Then sections were incubated with rat anti-L1 monoclonal antibody (1:200; Millipore, MAB5272) and rabbit anti-p-FIGQY (1:50) antibody at room temperature for 2 hours. Signals were developed by incubating sections with FITC-conjugated donkey anti-rat $\operatorname{IgG}$ (1:200; Jackson Immunoresearch) and TRITC-conjugated donkey anti-rabbit IgG (1:200; Jackson Immunoresearch) for 1 hour at room temperature. Images were obtained by Zeiss 710 confocal microscopy.

\section{L1-ankyrin recruitment assay}

Ankyrin recruitment to the plasma membrane of L1-transfected HEK293 cells was assayed as previously described (Needham et al., 2001). Briefly, HEK293T cells on poly-D-lysine coated Mat-Tek dishes were transfected with plasmid pEGFP-N1 expressing ankyrinGEGFP fusion protein, pcDNA3 plasmid expressing WT human L1 or pcDNA3 plasmid expressing mutant human $\mathrm{L}^{1229} \mathrm{H}$, and/or pcDNA3 plasmid expressing chicken EphB2 or EphB2 kinase dead mutant (Zisch et al., 1998) using Lipofectamine 2000. After 18 hr, some cultures were treated with mouse ephrinB1-Fc chimeric protein (R\&D Systems, Minneapolis, MN; $2 \mu \mathrm{g} / \mathrm{ml}$ ) or normal mouse IgG control ( $2 \mu \mathrm{g} / \mathrm{ml})$ for $15 \mathrm{~min}$. All cultures were fixed in $4 \%$ paraformaldehyde/PBS and blocked in $10 \%$ normal goat serum. Cultures were subjected to immunofluorescence staining with antibodies against extracellular region of L1 (mAb UJ127) or EphB2 (Zisch et al., 1998) using Cy3 donkey anti-mouse and Cy5 donkey anti-rabbit secondary antibodies, respectively. Confocal images were captured using the $488 \mathrm{~nm}$ excitation line of the laser for ankyrin-EGFP. Cells were scored in 3 or 4 replicate cultures for the percent of single-labeled (ankyrinG-EGFP), double-labeled (L1 or $\mathrm{L} 1 \mathrm{Y}^{1229} \mathrm{H}$, ankyrinG-EGFP) or triple-labeled (L1 or L1 $\mathrm{Y}^{1229} \mathrm{H}$, EphB2 or EphB2 KD, ankyrinG-EGFP) cells that display ankyrinG-EGFP recruited to the cell surface using 
criteria described in (Buhusi et al., 2003; Needham et al., 2001). Means \pm S.E.M. were compared for statistically significant differences using one-way ANOVA and Tukey's posthoc comparisons $(\mathrm{p}<0.001)$.

\section{Retinocollicular Axon Tracing}

Axonal tracing was performed as described previously (Demyanenko and Maness, 2003). L1Y ${ }^{1176}$ A mutant and WT littermates at P10-P12 were anesthetized and anterograde tracing was performed by focal injection of DiI (Invitrogen, Carlsbad, CA) as a 10\% solution in dimethylformamide into the peripheral region of the ventrotemporal retina using a picospritzer and glass micropipettes. After $48 \mathrm{~h}$, mice were anesthetized and perfused transcardially with $4 \%$ paraformaldehyde in $0.1 \mathrm{M}$ phosphate buffer $(\mathrm{pH} 7.4)$. Before removing the retina, the eye was visually inspected to identify the injection site and assess its position in the required quadrant relative to the extraocular muscles (lateral and inferior recti). The eyes were removed and incisions were made to demarcate the quadrants of the retina. Injected retinas, superior and inferior colliculi were whole-mounted and examined by epifluorescence microscopy. The injection sites covered 3-5\% of the retina. Termination zones (TZs) of labeled retinal axons in the superior colliculus were identified by their densely branched appearance under high magnification.

\section{Acknowledgments}

We thank Dr. Elena Pasquale (Sandford-Burnham Medical Research Institute) for providing EphB2 and EphB2 kinase-dead plasmids and Dr. Peter Brophy for providing Neurofascin antibody. This work was supported by the NSF grant 0923667 (Patricia F. Maness); the NIH grant 2R01 MH66332 (Mark Henkemeyer); the NIH grant HD39884 and HD057632 (Vance P. Lemmon).

\section{References}

Ango F, di Cristo G, Higashiyama H, Bennett V, Wu P, Huang ZJ. Ankyrin-based subcellular gradient of Neurofascin, an immunoglobulin family protein, directs GABAergic innervation at purkinje axon initial segment. Cell. 2004; 119:257-272. [PubMed: 15479642]

Boiko T, Vakulenko M, Ewers H, Yap CC, Norden C, Winckler B. Ankyrin-dependent and independent mechanisms orchestrate axonal compartmentalization of L1 family members Neurofascin and L1/neuron-glia cell adhesion molecule. J Neurosci. 2007; 27:590-603. [PubMed: 17234591]

Buhusi M, Midkiff BR, Gates AM, Richter M, Schachner M, Maness PF. Close homolog of L1 is an enhancer of integrin-mediated cell migration. J Biol Chem. 2003; 278:25024-25031. [PubMed: 12721290]

Buhusi M, Schlatter MC, Demyanenko GP, Thresher R, Maness PF. L1 interaction with ankyrin regulates mediolateral topography in the retinocollicular projection. J Neurosci. 2008; 28:177-188. [PubMed: 18171935]

Cheng L, Itoh K, Lemmon V. L1-mediated branching is regulated by two ezrin-radixin-moesin (ERM)-binding sites, the RSLE region and a novel juxtamembrane ERM-binding region. $\mathrm{J}$ Neurosci. 2005; 25:395-403. [PubMed: 15647482]

Davis JQ, Bennett V. Ankyrin binding activity shared by the Neurofascin/L1/NrCAM family of nervous system cell adhesion molecules. J Biol Chem. 1994; 269:27163-27166. [PubMed: 7961622]

Demyanenko GP, Maness PF. The L1 cell adhesion molecule is essential for topographic mapping of retinal axons. J Neurosci. 2003; 23:530-538. [PubMed: 12533613] 
Dickson TC, Mintz CD, Benson DL, Salton SR. Functional binding interaction identified between the axonal CAM L1 and members of the ERM family. J Cell Biol. 2002; 157:1105-1112. [PubMed: 12070130]

Feldheim DA, Kim YI, Bergemann AD, Frisen J, Barbacid M, Flanagan JG. Genetic analysis of ephrin-A2 and ephrin-A5 shows their requirement in multiple aspects of retinocollicular mapping. Neuron. 2000; 25:563-574. [PubMed: 10774725]

Feldheim DA, O'Leary DD. Visual map development: bidirectional signaling, bifunctional guidance molecules, and competition. Cold Spring Harb Perspect Biol. 2010; 2:a001768. [PubMed: 20880989]

Frisen J, Yates PA, McLaughlin T, Friedman GC, O’Leary DD, Barbacid M. Ephrin-A5 (AL-1/ RAGS) is essential for proper retinal axon guidance and topographic mapping in the mammalian visual system. Neuron. 1998; 20:235-243. [PubMed: 9491985]

Garver TD, Ren Q, Tuvia S, Bennett V. Tyrosine phosphorylation at a site highly conserved in the L1 family of cell adhesion molecules abolishes ankyrin binding and increases lateral mobility of Neurofascin. J Cell Biol. 1997; 137:703-714. [PubMed: 9151675]

Gil OD, Sakurai T, Bradley AE, Fink MY, Cassella MR, Kuo JA, Felsenfeld DP. Ankyrin binding mediates L1CAM interactions with static components of the cytoskeleton and inhibits retrograde movement of L1CAM on the cell surface. J Cell Biol. 2003; 162:719-730. [PubMed: 12925712]

Godenschwege TA, Kristiansen LV, Uthaman SB, Hortsch M, Murphey RK. A conserved role for Drosophila Neuroglian and human L1-CAM in central-synapse formation. Curr Biol. 2006; 16:1223. [PubMed: 16401420]

Hansen MJ, Dallal GE, Flanagan JG. Retinal axon response to ephrin-as shows a graded, concentration-dependent transition from growth promotion to inhibition. Neuron. 2004; 42:717730. [PubMed: 15182713]

He Y, Jensen GJ, Bjorkman PJ. Cryo-electron tomography of homophilic adhesion mediated by the neural cell adhesion molecule L1. Structure. 2009; 17:460-471. [PubMed: 19278660]

Henkemeyer M, Orioli D, Henderson JT, Saxton TM, Roder J, Pawson T, Klein R. Nuk controls pathfinding of commissural axons in the mammalian central nervous system. Cell. 1996; 86:3546. [PubMed: 8689685]

Hindges R, McLaughlin T, Genoud N, Henkemeyer M, O’Leary DD. EphB forward signaling controls directional branch extension and arborization required for dorsal-ventral retinotopic mapping. Neuron. 2002; 35:475-487. [PubMed: 12165470]

Hortsch M, Nagaraj K, Godenschwege TA. The interaction between L1-type proteins and ankyrins--a master switch for L1-type CAM function. Cell Mol Biol Lett. 2009; 14:57-69. [PubMed: 18839070]

Ignelzi MA Jr. Miller DR, Soriano P, Maness PF. Impaired neurite outgrowth of src-minus cerebellar neurons on the cell adhesion molecule L1. Neuron. 1994; 12:873-884. [PubMed: 7512817]

Itofusa R, Kamiguchi H. Polarizing membrane dynamics and adhesion for growth cone navigation. Mol Cell Neurosci. 2011; 48:332-338. [PubMed: 21459144]

Jenkins SM, Kizhatil K, Kramarcy NR, Sen A, Sealock R, Bennett V. FIGQY phosphorylation defines discrete populations of $\mathrm{L} 1$ cell adhesion molecules at sites of cell-cell contact and in migrating neurons. J Cell Sci. 2001; 114:3823-3835. [PubMed: 11719549]

Kalus I, Schnegelsberg B, Seidah NG, Kleene R, Schachner M. The proprotein convertase PC5A and a metalloprotease are involved in the proteolytic processing of the neural adhesion molecule L1. $\mathrm{J}$ Biol Chem. 2003; 278:10381-10388. [PubMed: 12529374]

Kamiguchi H, Lemmon V. A neuronal form of the cell adhesion molecule L1 contains a tyrosinebased signal required for sorting to the axonal growth cone. J Neurosci. 1998; 18:3749-3756. [PubMed: 9570805]

Kamiguchi H, Long KE, Pendergast M, Schaefer AW, Rapoport I, Kirchhausen T, Lemmon V. The neural cell adhesion molecule L1 interacts with the AP-2 adaptor and is endocytosed via the clathrin-mediated pathway. J Neurosci. 1998; 18:5311-5321. [PubMed: 9651214]

Kizhatil K, Wu YX, Sen A, Bennett V. A new activity of doublecortin in recognition of the phosphoFIGQY tyrosine in the cytoplasmic domain of Neurofascin. J Neurosci. 2002; 22:7948-7958. [PubMed: 12223548] 
Lemke G, Reber M. Retinotectal mapping: new insights from molecular genetics. Annu Rev Cell Dev Biol. 2005; 21:551-580. [PubMed: 16212507]

Maness PF, Schachner M. Neural recognition molecules of the immunoglobulin superfamily: signaling transducers of axon guidance and neuronal migration. Nat Neurosci. 2007; 10:19-26. [PubMed: 17189949]

McFarlane S, Cornel E, Amaya E, Holt CE. Inhibition of FGF receptor activity in retinal ganglion cell axons causes errors in target recognition. Neuron. 1996; 17:245-254. [PubMed: 8780648]

McLaughlin T, Hindges R, Yates PA, O'Leary DD. Bifunctional action of ephrin-B1 as a repellent and attractant to control bidirectional branch extension in dorsal-ventral retinotopic mapping. Development. 2003; 130:2407-2418. [PubMed: 12702655]

Mechtersheimer S, Gutwein P, Agmon-Levin N, Stoeck A, Oleszewski M, Riedle S, Postina R, Fahrenholz F, Fogel M, Lemmon V, Altevogt P. Ectodomain shedding of L1 adhesion molecule promotes cell migration by autocrine binding to integrins. J Cell Biol. 2001; 155:661-673. [PubMed: 11706054]

Mintz CD, Carcea I, McNickle DG, Dickson TC, Ge Y, Salton SR, Benson DL. ERM proteins regulate growth cone responses to Sema3A. J Comp Neurol. 2008; 510:351-366. [PubMed: 18651636]

Moos M, Tacke R, Scherer H, Teplow D, Fruh K, Schachner M. Neural adhesion molecule L1 as a member of the immunoglobulin superfamily with binding domains similar to fibronectin. Nature. 1988; 334:701-703. [PubMed: 3412448]

Nakamura Y, Lee S, Haddox CL, Weaver EJ, Lemmon VP. Role of the cytoplasmic domain of the L1 cell adhesion molecule in brain development. J Comp Neurol. 2010; 518:1113-1132. [PubMed: 20127821]

Needham LK, Thelen K, Maness PF. Cytoplasmic domain mutations of the L1 cell adhesion molecule reduce L1-ankyrin interactions. J Neurosci. 2001; 21:1490-1500. [PubMed: 11222639]

Nishimura K, Yoshihara F, Tojima T, Ooashi N, Yoon W, Mikoshiba K, Bennett V, Kamiguchi H. L1dependent neuritogenesis involves ankyrinB that mediates L1-CAM coupling with retrograde actin flow. J Cell Biol. 2003; 163:1077-1088. [PubMed: 14657231]

Orioli D, Henkemeyer M, Lemke G, Klein R, Pawson T. Sek4 and Nuk receptors cooperate in guidance of commissural axons and in palate formation. EMBO J. 1996; 15:6035-6049. [PubMed: 8947026]

Poliakov A, Cotrina ML, Pasini A, Wilkinson DG. Regulation of EphB2 activation and cell repulsion by feedback control of the MAPK pathway. J Cell Biol. 2008; 183:933-947. [PubMed: 19047466]

Poopalasundaram S, Marler KJ, Drescher U. EphrinA6 on chick retinal axons is a key component for p75(NTR)-dependent axon repulsion and TrkB-dependent axon branching. Mol Cell Neurosci. 2011; 47:131-136. [PubMed: 21463686]

Schaefer AW, Kamei Y, Kamiguchi H, Wong EV, Rapoport I, Kirchhausen T, Beach CM, Landreth G, Lemmon SK, Lemmon V. L1 endocytosis is controlled by a phosphorylationdephosphorylation cycle stimulated by outside-in signaling by L1. J Cell Biol. 2002; 157:12231232. [PubMed: 12082080]

Schlatter MC, Buhusi M, Wright AG, Maness PF. CHL1 promotes Sema3A-induced growth cone collapse and neurite elaboration through a motif required for recruitment of ERM proteins to the plasma membrane. J Neurochem. 2008; 104:731-744. [PubMed: 17995939]

Schmidt JT. Activity-driven sharpening of the retinotectal projection: the search for retrograde synaptic signaling pathways. J Neurobiol. 2004; 59:114-133. [PubMed: 15007831]

Simon DK, O'Leary DD. Influence of position along the medial-lateral axis of the superior colliculus on the topographic targeting and survival of retinal axons. Brain Res Dev Brain Res. 1992; 69:167-172.

Stettler EM, Galileo DS. Radial glia produce and align the ligand fibronectin during neuronal migration in the developing chick brain. J Comp Neurol. 2004; 468:441-451. [PubMed: 14681936]

Suh LH, Oster SF, Soehrman SS, Grenningloh G, Sretavan DW. L1/Laminin modulation of growth cone response to EphB triggers growth pauses and regulates the microtubule destabilizing protein SCG10. J Neurosci. 2004; 24:1976-1986. [PubMed: 14985440] 
Thakar S, Chenaux G, Henkemeyer M. Critical roles for EphB and ephrin-B bidirectional signalling in retinocollicular mapping. Nat Commun. 2011; 2:431. [PubMed: 21847105]

Tuvia S, Garver TD, Bennett V. The phosphorylation state of the FIGQY tyrosine of Neurofascin determines ankyrin-binding activity and patterns of cell segregation. Proc Natl Acad Sci U S A. 1997; 94:12957-12962. [PubMed: 9371782]

Vindis C, Cerretti DP, Daniel TO, Huynh-Do U. EphB1 recruits c-Src and p52Shc to activate MAPK/ERK and promote chemotaxis. J Cell Biol. 2003; 162:661-671. [PubMed: 12925710]

Wang SW, Mu X, Bowers WJ, Klein WH. Retinal ganglion cell differentiation in cultured mouse retinal explants. Methods. 2002; 28:448-456. [PubMed: 12507463]

Whittard JD, Sakurai T, Cassella MR, Gazdoiu M, Felsenfeld DP. MAP kinase pathway-dependent phosphorylation of the L1-CAM ankyrin binding site regulates neuronal growth. Mol Biol Cell. 2006; 17:2696-2706. [PubMed: 16597699]

Wisco D, Anderson ED, Chang MC, Norden C, Boiko T, Folsch H, Winckler B. Uncovering multiple axonal targeting pathways in hippocampal neurons. J Cell Biol. 2003; 162:1317-1328. [PubMed: 14517209]

Yap CC, Nokes RL, Wisco D, Anderson E, Folsch H, Winckler B. Pathway selection to the axon depends on multiple targeting signals in NgCAM. J Cell Sci. 2008; 121:1514-1525. [PubMed: 18411247]

Yates PA, Roskies AL, McLaughlin T, O'Leary DD. Topographic-specific axon branching controlled by ephrin-As is the critical event in retinotectal map development. J Neurosci. 2001; 21:85488563. [PubMed: 11606643]

Zisch AH, Kalo MS, Chong LD, Pasquale EB. Complex formation between EphB2 and Src requires phosphorylation of tyrosine 611 in the EphB2 juxtamembrane region. Oncogene. 1998; 16:26572670. [PubMed: 9632142]

Zisch AH, Pazzagli C, Freeman AL, Schneller M, Hadman M, Smith JW, Ruoslahti E, Pasquale EB. Replacing two conserved tyrosines of the EphB2 receptor with glutamic acid prevents binding of SH2 domains without abrogating kinase activity and biological responses. Oncogene. 2000; 19:177-187. [PubMed: 10644995]

Zisch AH, Stallcup WB, Chong LD, Dahlin-Huppe K, Voshol J, Schachner M, Pasquale EB. Tyrosine phosphorylation of L1 family adhesion molecules: implication of the Eph kinase Cek5. J Neurosci Res. 1997; 47:655-665. [PubMed: 9089215] 
A

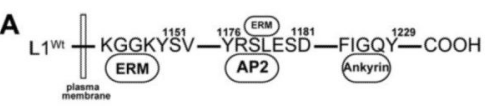

C

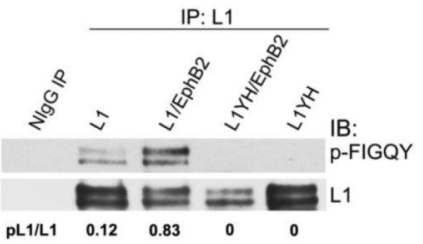

E

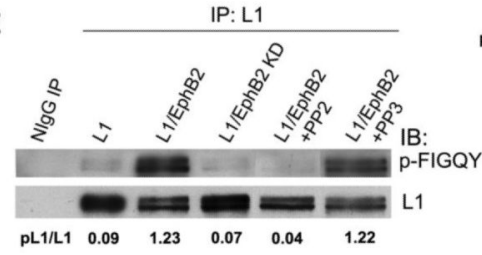

B

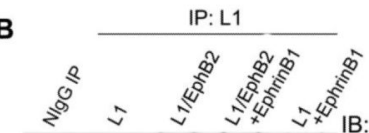

$\because \Rightarrow \mathrm{p}-\mathrm{FIGQY}$

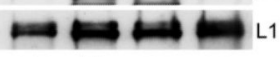

$\begin{array}{lllll}\mathrm{pL} 1 / \mathrm{L} 1 & 0.10 & 0.70 & 0.63 & 0.08\end{array}$

D

IP: L1

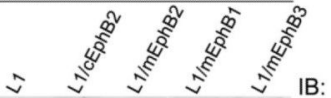

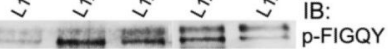

$=0=0=\mathrm{L} 1$

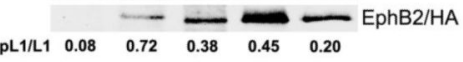

$\mathbf{F}$

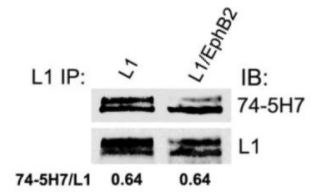

Figure 1. EphB2 receptor mediates tyrosine phosphorylation of L1 at FIGQY motif A. Location of tyrosine-containing motifs in the L1 cytoplasmic domain that bind ezrinradixin-moesin (ERM) proteins, the clathrin adaptor AP2, and ankyrin. B-E. Immunoblotting (IB) with p-FIGQY antibody in L1 immunoprecipitates (IP) from transfected HEK293 cells or control precipitates with nonimmune $\operatorname{IgG}(\mathrm{NIgG})$. Ratios of phosphorylated L1 to $\mathrm{L} 1$ protein (pL1/L1) were obtained by densitometry after reprobing with L1 antibody.

(B) Expression of L1 and EphB2 increased L1 phosphorylation at FIGQY in transfected HEK293 cells compared to cells expressing only L1. Addition of ephrinB1 to cells did not further increase p-FIGQY in L1.

(C) p-FIGQY antibody did not recognize L1 immunoprecipitated from HEK293 cells transfected with $\mathrm{L} 1 \mathrm{Y}^{1229} \mathrm{H}(\mathrm{L} 1 \mathrm{YH})$ with or without EphB2 co-expression.

(D) Mouse mEphB2, mEphB1 (HA-tagged) and mEphB3 (HA-tagged) induced phosphorylation of L1 at FIGQY when expressed in HEK293 cells, while chick cEphB2 was the most effective (top panel). mEphB2, cEphB2, mEphB1-HA, and mEphB3-HA each coimmunoprecipitated with L1 as shown by immmunoblotting of L1 immunoprecipitates with EphB2 antibodies or anti-HA antibody (lowest panel).

(E) EphB2 kinase activity was required for phosphorylation of FIGQY, as EphB2 kinase dead mutant (EphB2 KD) did not induce p-FIGQY in L1-expressing HEK293 cells. The Src kinase inhibitor PP2 decreased phosphorylation of L1 in L1/EphB2 co-transfected HEK293 cells, while the nonfunctional analog PP3 had no effect.

(F) EphB2 did not induce tyrosine phosphorylation of L1 at $\mathrm{Y}^{1176} \mathrm{RSL}$ in HEK293 cells, as indicated by equal levels of non-phosphorylated $\mathrm{Y}^{1176} \mathrm{RSL}$ in $\mathrm{L} 1$ detected by $74-5 \mathrm{H} 7$ antibody, which specifically recognizes the non-phosphorylated motif. 


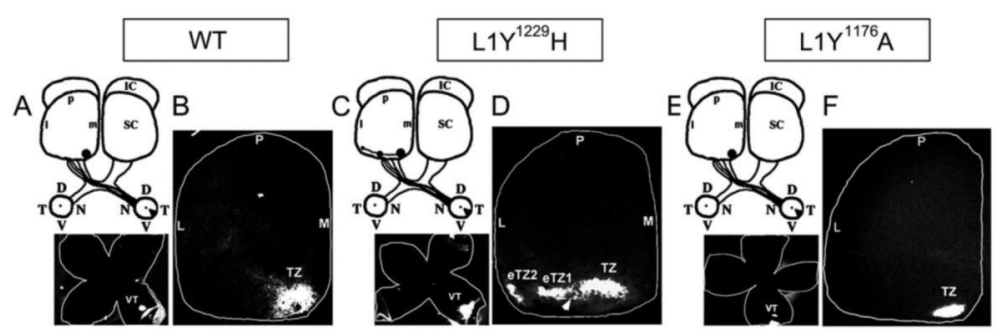

Figure 2. Normal retinocollicular mapping of $\mathrm{L1Y}^{1176} \mathrm{~A}$ mutant mice

A-B. Injection of DiI into the peripheral ventro-temporal (VT) retina of WT mice (P10) labeled a single termination zone (TZ) in the anteromedial superior colliculus (SC) at P12. C-D. DiI injection into the ventro-temporal retina of homozygous $\mathrm{L}_{1} \mathrm{Y}^{1229} \mathrm{H}$ mutant mice showed multiple laterally-shifted ectopic TZs (eTZs) in the anterior SC.

E-F. DiI injection into the ventro-temporal retina of homozygous L1 $\mathrm{Y}^{1176} \mathrm{~A}$ mutant mice showed only a single normal $\mathrm{TZ}$ in the anteromedial SC.

The position of injections is shown in flat mounts of the retina below each scheme. $(\mathrm{L}$, lateral; M, medial; A, anterior; P, posterior; D, dorsal; V, ventral; N, nasal; T, temporal; IC, inferior colliculus) 

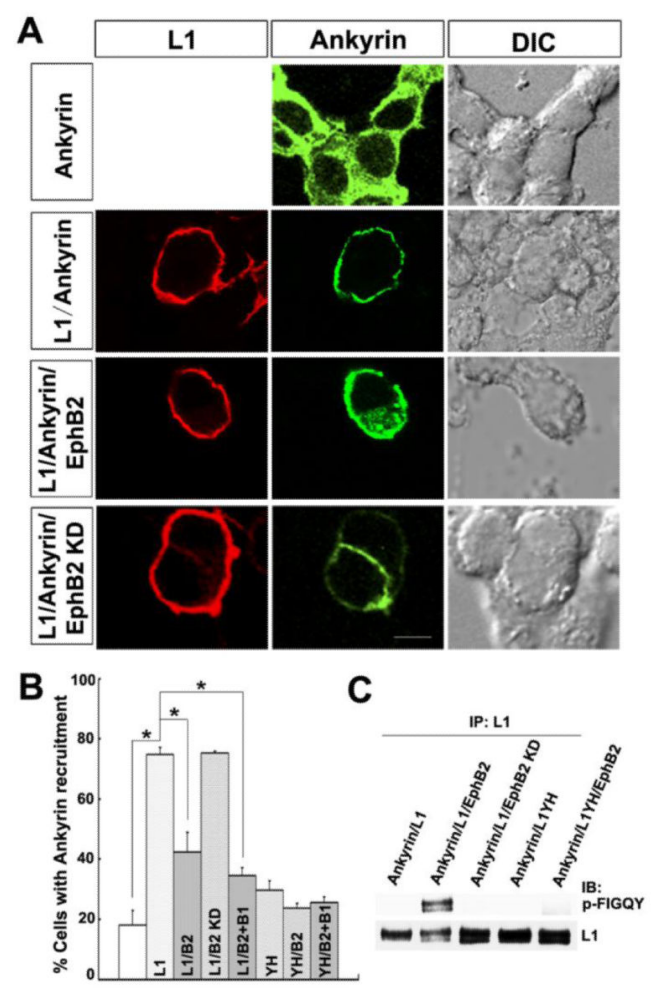

Figure 3. EphB2 kinase inhibits recruitment of ankyrin to cell membrane of L1-expression cells in a cytofluorescence assay

A. Immunofluorescence staining for L1 in the plasma membrane of transfected HEK293 cells (left column, red) and EGFP-ankyrinG fluorescence (middle column, green) showed that EGFP-ankyrinG had a cytoplasmic distribution when expressed alone (Ankyrin), while L1 expression recruited EGFP-ankyrinG to the cell membrane (L1/Ankyrin). EGFP-ankyrin remainedG cytoplasmic when L1 was co-expressed with EphB2 (L1/Ankyrin/EphB2) but not with EphB2 KD (L1/Ankyrin/EphB2 KD).

Right column shows differential interference contrast (DIC) images. Scale bar=10 um B. Quantification of percentage of cells showing ankyrin recruitment to the plasma membrane demonstrated that L1 increased ankyrin recruitment to the membrane in cells coexpressing L1 and ankyrinG compared to ankyrinG alone (L1/ankyrin: $75 \pm 2 \%$; ankyrin: 18 $\pm 5 \%$; one-way ANOVA, Tukey's post-hoc test, *p<0.001).

Recruitment decreased in L1/ankyrin/EphB2 expressing cells (42 $\pm 6 \%$ ) compared to L1/ ankyrin $(* \mathrm{p}<0.001)$. There was no decrease of recruitment in L1/ankyrin/EphB2 KD $(75 \pm$ $0.5 \%)$ compared to L1/ankyrin expressing cells. EphrinB1 treatment $(35 \pm 3 \%)$ reduced ankyrin recruitment to a small extent in L1/ankyrin expressing cells $(* \mathrm{p}<0.001)$. No significant difference was detected between ankyrin alone and negative controls of ankyrin/L1 $\mathrm{Y}^{1229} \mathrm{H}(29 \pm 3 \%)$, ankyrin/L1 $\mathrm{Y}^{1229} \mathrm{H} / \mathrm{EphB} 2(24 \pm 1.5 \%)$ or ankyrin/L1Y ${ }^{1229} \mathrm{H} /$ EphB2 + ephrinB1 $(26 \pm 2 \%)(\mathrm{p}>0.05)$.

(Labeling on bars indicate cells transfected with ankyrinG alone (first bar), L1/ankyrin (L1), L1/ankyrin/EphB2 (L1/B2), L1/ankyrin/EphB2 KD (L1/B2 KD), L1/ankyrin/ EphB2+ephrinB1 (L1/B2+B1), L1 ${ }^{1229} \mathrm{H} / \operatorname{ankyrin}(\mathrm{YH}), \mathrm{L} 1 \mathrm{Y}^{1229} \mathrm{H} /$ ankyrin/EphB2 (YH/ B2), L1 ${ }^{1229} \mathrm{H} /$ ankyrin/EphB2+ephrinB1 (YH/B2+B1). 
C. L1 is phosphorylated by EphB2 at the FIGQY motif in ankyrin-expressing HEK293 cells. Under the conditions of the ankyrin recruitment assay, EGFP-ankyrinG expressing HEK293 cells were co-transfected with L1, L1/EphB2, L1/EphB2 KD, L1YH, or L1YH/EphB2. L1 was immunoprecipitated from equal amounts of cell lysates $(500 \mu \mathrm{g})$ and immunoblotted with p-FIGQY antibodies, then blots were stripped and reprobed with L1 antibodies. EphB2, but not EphB2 KD, induced L1 phosphorylation at FIGQY, while L1YH was not phosphorylated by EphB2. 

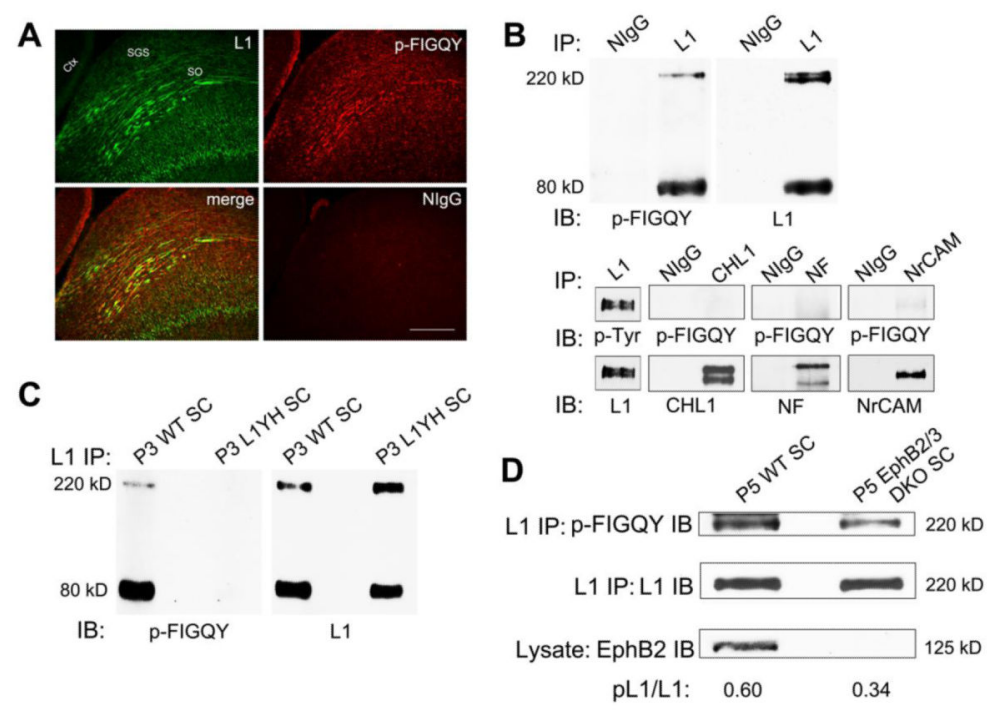

Figure 4. L1 FIGQY motif is phosphorylated in retina ganglion cell axons in the superior colliculus

A. In WT mice (P7), immunofluorescence staining for p-FIGQY (red) in sagittal sections through the SC co-localized in part with L1 (green) in fibers within the superficial retinorecipient layers (SGS and SO) where RGC axons track, as indicated in merged images. PFIGQY staining was also seen in some fibers in the retino-recipient layers, and in deeper layers of the SC. No staining was detected with normal rabbit IgG. Scale bar $=200 \mu \mathrm{m}$. (SGS, stratum griseum superificiale; SO, stratum opticum; Ctx, cerebral cortex) B. p-FIGQY antibody recognized full length L1 $(220 \mathrm{kDa})$ and its principal C-terminal cleavage fragment $(80 \mathrm{kDa})$ in the $\mathrm{SC}$, as shown by immunoblotting in $\mathrm{L} 1$ immunoprecipitates from WT SC lysates (P3) (upper panel). The p-FIGQY antibody also recognized NrCAM to a lesser extent but not CHL1 or Neurofascin (NF) immunoprecipitated from P3 SC (lower panel).

No bands were detected in normal mouse IgG precipitates in any sample.

C. p-FIGQY antibody did not recognize L1 immunoprecipitated from L1YH mutant SC (P3).

D. The relative level of p-FIGQY in full length $220 \mathrm{kDa} \mathrm{L1}$ was decreased in L1 immunoprecipitated from EphB2/B3 double null mutant SC (P5) compared to WT SC. EphB2 protein was undetectable in EphB2/B3 double mutant SC. 


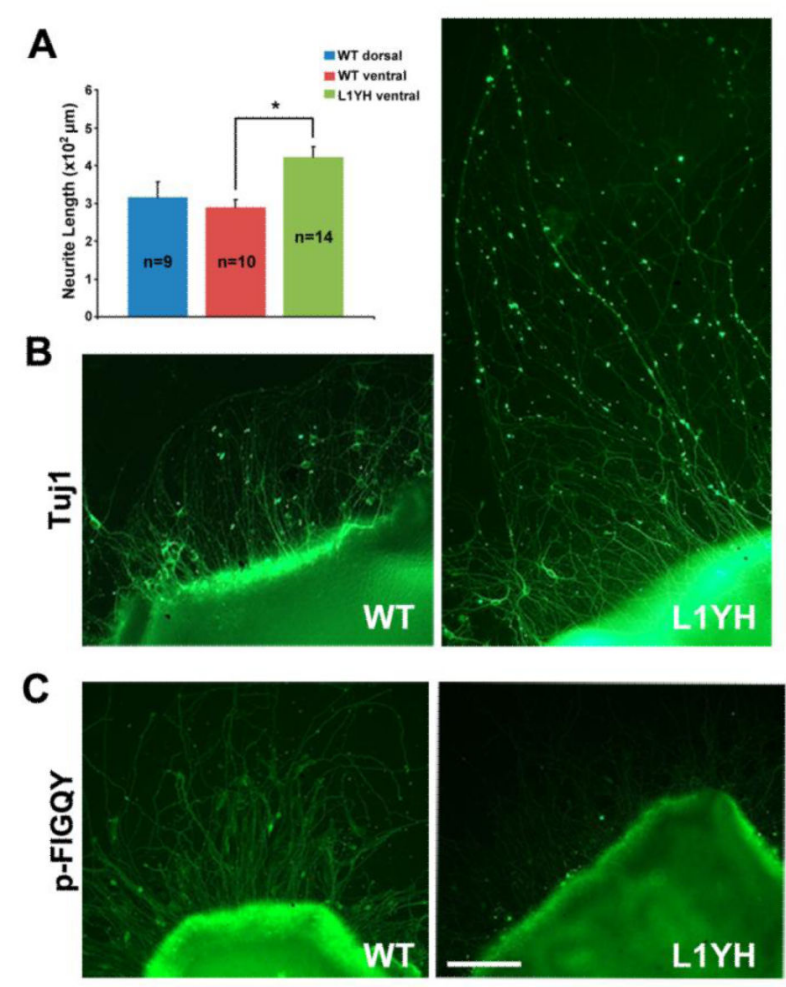

Figure 5. Increased outgrowth of retinal axons from $\operatorname{L1Y}^{1229} \mathrm{H}$ mice in explants cultures from ventral retina

A. Quantification of mean neurite length of TuJ1-positive neurites extending from ventral retinal explants demonstrated that outgrowth of RGC axons from $\mathrm{L}_{1} \mathrm{Y}^{1229} \mathrm{H}$ mice was significantly greater than that of WT mice ( $t$-test, $\left.{ }^{*} \mathrm{p}<0.001\right)$. There was no significant difference in mean neurite length between WT dorsal and WT vental retinal explants. $\mathrm{n}=$ number of mice of each genotype.

B. Ventral retina explants from $\mathrm{L} 1 \mathrm{Y}^{1229} \mathrm{H}$ mutant mice showed RGC axons extending far from the explants edge in addition to some of comparable length compared to WT, indicated by immunostaining with neuronal marker TuJ1.

C. Immunostaining of ventral retinal explant cultures from WT and $\mathrm{L}^{1} \mathrm{Y}^{1229} \mathrm{H}$ mutant mice with p-FIGQY antibody showed no staining of L1YH mutant axons, while strong p-FIGQY staining was seen in WT axons.

Scale bar $=100 \mu \mathrm{m}$ in B-C. 


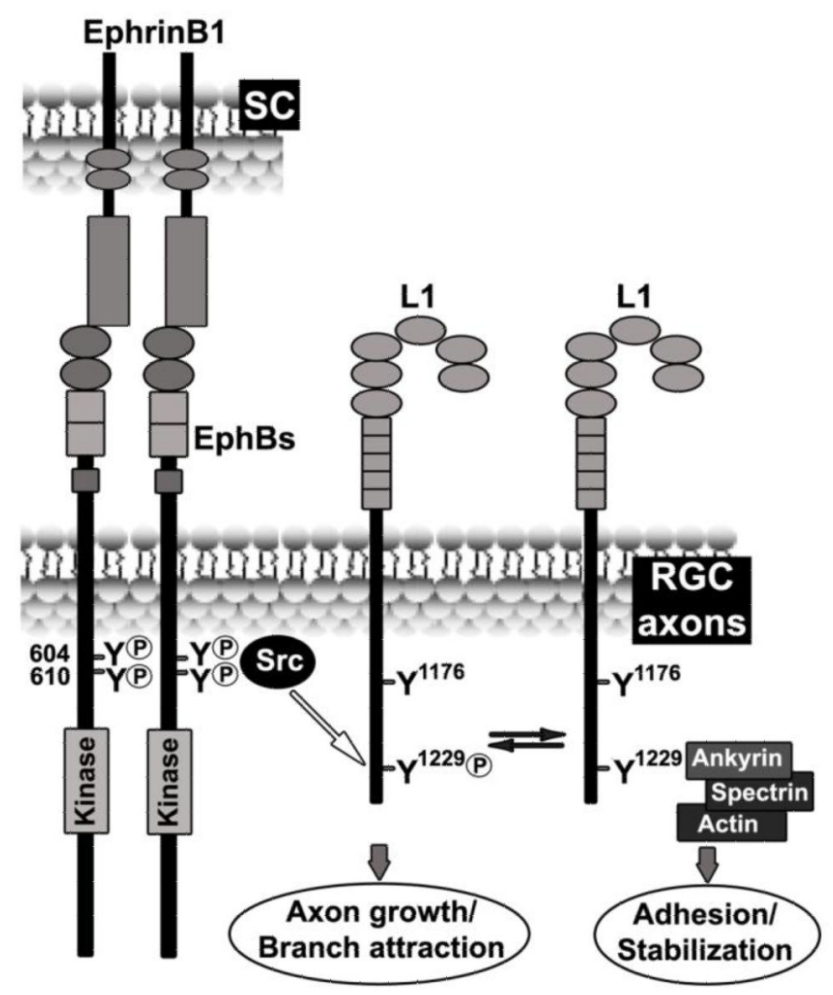

Figure 6. Model for the regulation of L1-Ankyrin binding by ephrinB1/EphBs through tyrosine phosphorylation at the FIGQY domain during mouse retinocollicular targeting During retinal ganglion cell (RGC) axon targeting in superior colliculus (SC), forward ephrinB1/EphB signaling recruits Src kinase to phosphorylated tyrosine residues 604/610 in the juxtamembrane of mouse EphB2 to induce L1-Y ${ }^{1229}$ tyrosine phosphorylation, potentially facilitating RGC axon growth and/or branch attraction to future termination zones. Reversible dephosphorylation of L1-Y ${ }^{1229}$ enables L1 to bind ankyrin through spectrin linkage to the actin cytoskeleton, which may promote adhesion and stabilization of synaptic terminals. Tyrosine $\mathrm{Y}^{1176}$ on L1 is not regulated by ephrinB1/EphB signaling and is dispensible for RGC axon mapping in the SC. 